\title{
Reaction of Swiss Term Premia to Monetary Policy Surprises
}

\author{
PAul SöDERLind ${ }^{a}$
}

JEL-Classification: E27, E47

Keywords: affine price of risk, interest rate caps, survey data

\section{Introduction}

This paper uses a yield curve model to perform a kind of "event study" - with the objective of understanding how bond term (risk) premia are affected by monetary policy moves. The event study amounts to estimating the typical joint movements of the yield curve factors on days with monetary policy decisions and then tracing out the implications of those movements for yields and term premia.

A traditional event study of the effects of monetary policy surprises on the yield curve can reveal many interesting facts (see, for instance, RANALDO and Rossi, 2010). However, it cannot say much about why long yields change: is it because of expected future short rates or term premia? I try to overcome this by performing the event study within the confines of an estimated yield curve model.

This yield curve model is estimated on daily financial data. This stands in contrast to most macro-finance models (see, for instance, ANG and PIAZZESI, 2003, and Hördahl, Tristiani, and Vestin, 2006), which are typically estimated on monthly data and usually include also macro data. For instance, LiLDholdt, Panigirtzoglou, and Peacock (2007) and Chun (2005) show that term premia may be related to the output and inflation. The current paper uses only financial data, since the event study method requires daily data to get precise measures of monetary policy shocks. The focus of the current paper is thus on short-run movements.

The estimated yield curve model is driven by two latent factors and two optionbased risk factors. The latter are assumed to drive the time variation of the term

a University of St. Gallen and CEPR. Address: SBF, University of St. Gallen, Rosenbergstrasse 52, CH-9000 St. Gallen, Switzerland.E-mail: Paul.Soderlind@unisg.ch. I thank Christopher Meyer and Angelo Ranaldo for data and discussions; Eric Jondeau, Michael Fischer, Carlos Lenz and Nikola Mirkov for comments. 
premia. Overall, the estimated model appears to fit data well. The pricing errors are small and the average yield curve is well captured. The model also generates interest rate changes that square well with independent evidence on monetary policy surprises and yield curve slopes that fit the time series pattern of survey based measures of term premia.

By feeding the model with the typical pattern observed in the factors on days with monetary policy decisions, the responses of yields and term premia are traced out. Among other things, the results show that an increase of the policy rate typically leads to small increases of the term premia for short/medium maturities and a reasonably sized decrease of the term premia for long maturities.

The outline of the paper is as follows. Section 2 presents the data; Section 3 summarises the yield curve model; Section 4 discusses the estimation method; Section 5 presents the empirical results and Section 6 concludes. Some technical details are relegated to the appendix.

\section{Data}

The main data used in this paper consists of Swiss interest rates and interest rate caps (options). The sample is daily (excluding weekends) and covers the period from 15 January 2002 to 31 May 2009. The starting date is due to limited availability of reliable data on the interest rate caps.

The yield data for maturities from one week to one year $(1 \mathrm{w}, 1 \mathrm{~m}, 2 \mathrm{~m}, 3 \mathrm{~m}, 6 \mathrm{~m}$, $9 \mathrm{~m}, 12 \mathrm{~m}$ ) are based on Libor rates and for maturities from 2 to 10 years on the zero coupon yields from swaps (provided by Datastream). All yields are converted into continuously compounded yields.

The upper panel of Figure 1 shows all the yield data and the lower panel shows the term spread between the 10-year yield and the 3-month yield. In this sample, the term spread is always positive, but changes over time. There are two possible explanations for a positive spread: expected future short rates are higher than the current short rate and/or long rates are affected by (risk) term premia. The spread is always positive in this sample, which suggests that term premia are important.

An interest rate cap is a portfolio of call options ("caplets") on future interest rates. For instance, a one-year cap consists of three options on 3-month interest rates, starting 3, 6 and 9 months ahead respectively. Each of these options pays the difference between the 3-month rate and the cap rate (say, 1\%) if the difference is positive and zero otherwise. A cap can therefore be used to guarantee that the effective interest rate cost on a floating rate loan does not exceed the 
Figure 1: Zero Coupon Yields and Term Spread

The upper panel shows continuously compounded zero coupon rates based on Libor $(1 \mathrm{w}-12 \mathrm{~m})$ rates and swap rates $(2 \mathrm{y}-10 \mathrm{y})$. The lower panel shows the yield spread between the $10 \mathrm{y}$ rate and the $3 \mathrm{~m}$ rate.
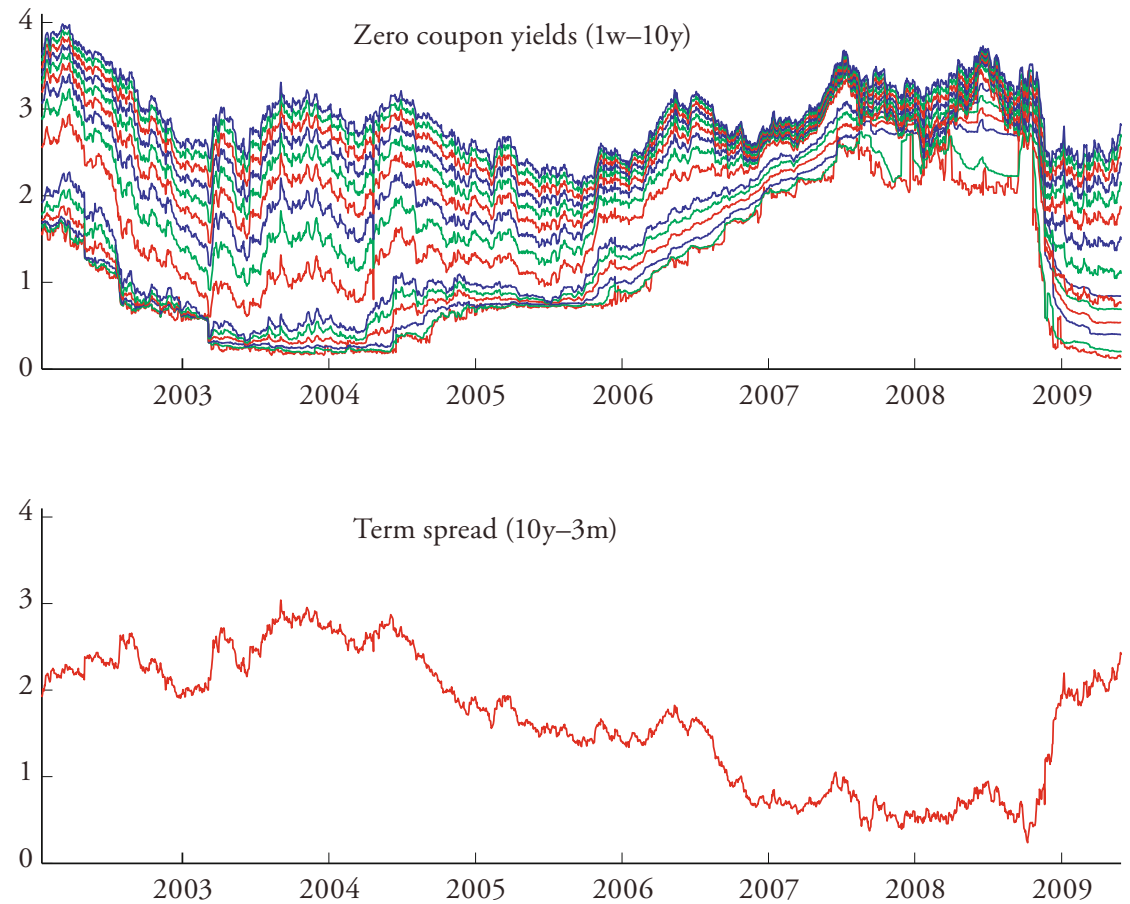

cap rate. Clearly, this insurance comes at a price, which by market conventions is quoted as an implied volatility (the annualized volatility such that the BlackScholes formula applied to each of the options would generate the same price as the actual market price). Figure 2 shows the implied volatilities (from Bloomberg) for a 1-year cap (upper panel) and a 5-year cap (lower panel). The different curves represent different cap rates, from $0.5 \%$ to $5.5 \%$.

Table 1 shows the correlations between the 5-day change of the 3-month yield and other variables. For the full sample, the correlation with the term spread is -0.39 while the correlations with the implied volatilities (median value across cap rates) are negative but close to zero. Around days with monetary policy decisions, the correlations with the term spread and the 5-year implied volatility are 
Figure 2: Implied Volatilities of Rate Interest Caps, Cap Rates of 0.5\% to 5.5\%

The upper (lower) panel shows the implied volatilities for $1 \mathrm{y}(5 \mathrm{y})$ interest rate caps.
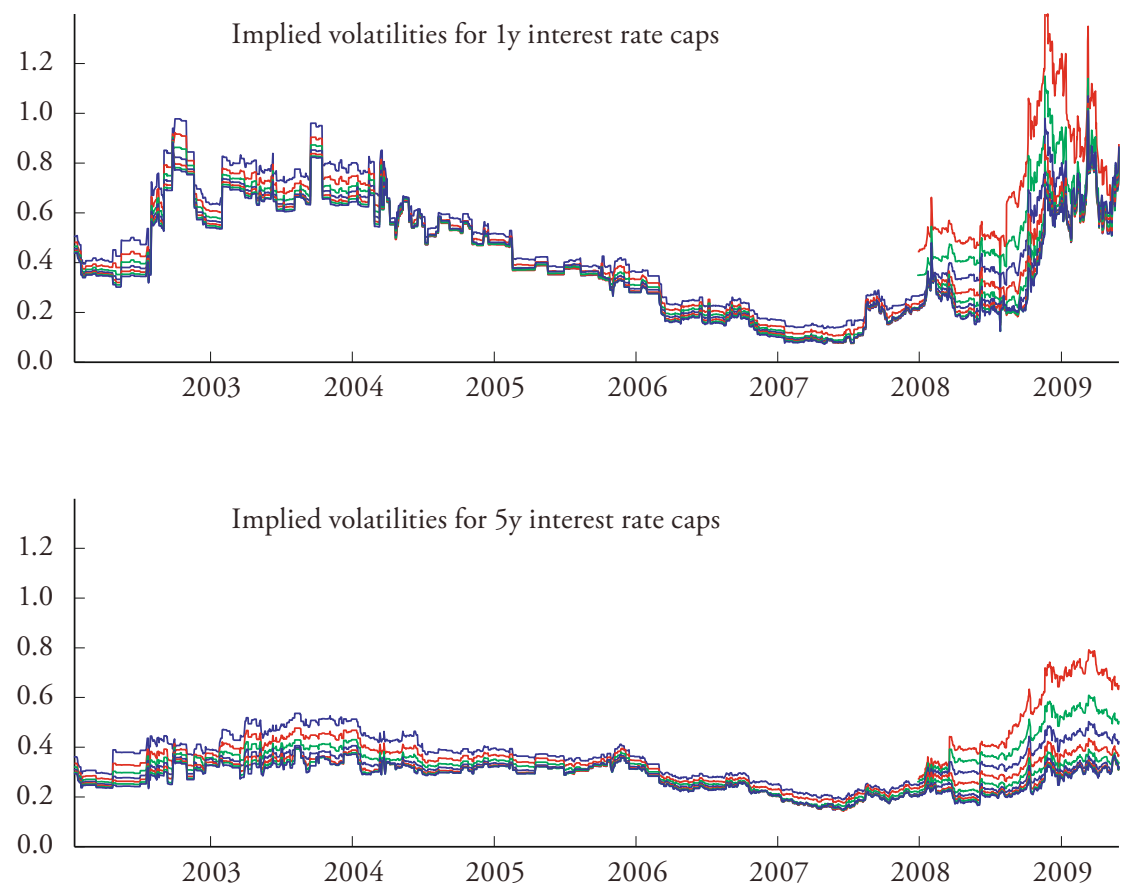

Table 1: Correlation between the 5-Day Change of the 3-Month Yield and other Variables

This table shows the correlations of the 5-day change of the 3-month yield with the 5-day change of other variables. For the dates with monetary policy decisions $(t)$, the change is measured as $x_{t+2}-x_{t-2}$.

\begin{tabular}{lcc}
\hline & Full sample & Around monetary policy decisions \\
\hline Term spread (10-year minus 3-month) & -0.39 & -0.71 \\
Implied volatility, 1-year & -0.09 & -0.18 \\
Implied volatility, 5-year & -0.06 & -0.42 \\
\hline
\end{tabular}


much more negative $(-0.71$ and -0.42 , respectively). In contrast, the correlation with the 1-year implied volatility decreases only a little. This suggests that the information content in the monetary policy decisions is distinctly different compared to most other drivers of the 3-month rate. In particular, it seems as if higher policy rates are associated with a downward tilt of the yield curve (as short rates increase more than long ones) and also with lower implied long-run volatilities.

\section{The Yield Curve Model}

This section presents the theoretical foundation of the yield curve model.

This is an affine yield curve model where the market price of risk is linear in the factors (see Duffee, 2002). It contains an explicit modelling of the pricing kernel and there are no arbitrage opportunities. ${ }^{1}$ The building blocks are the following:

$$
\begin{aligned}
y_{1 t} & =a_{1}+b_{1}^{\prime} x_{t}, \\
-m_{t+1} & =y_{1 t}-\chi_{t+1}, \\
\chi_{t+1} & =-\theta_{t}^{\prime} \theta_{t} / 2-\theta_{t}^{\prime} \varepsilon_{t+1}, \text { with } \varepsilon_{t+1} \sim N(0, I), \\
\theta_{t} & =\theta^{0}+\theta^{1} x_{t}, \text { and } \\
x_{t+1} & =(I-\Psi) \mu+\Psi x_{t}+S \varepsilon_{t+1} .
\end{aligned}
$$

First, the short rate $\left(y_{1 t}\right)$ is an affine function of the factors $\left(x_{t}\right.$, a vector). Second, the log stochastic discount factor $\left(m_{t+1}\right)$ is written in terms of the short rate (basically representing the conditional mean) and a term representing systematic risk $\left(\chi_{t+1}\right)$. Third, the systematic risk depends on the market prices of risk $\left(-\theta_{t}\right.$, which is predetermined) and normally distributed innovations $\left(\varepsilon_{t+1}\right)$. Fourth, the market prices of risk depend on the state variables. Fifth, the factors follow independent $\mathrm{AR}(1)$ processes ( $\Psi$ and $S$ are diagonal matrices).

It can be shown that the solution of the model is that all yields are affine functions of the state variables. For instance, the yield for maturity $n$ is

$$
y_{n t}=a_{n}+b_{n}^{\prime} x_{t}
$$

1 However, BoLDER and LIU (2007) argue that imposing no-arbitrage restrictions might hurt the empirical performance (for instance, in forecasting) compared to more agnostic models like Diebold and Li (2003). 
where $a_{n}$ and $b_{n}$ can be calculated from the parameters in (1). (See the appendix for details.)

In practice, I use a 4-factor system where the short rate and the market prices of risk are defined as

$$
\begin{gathered}
y_{1 t}=\left[\begin{array}{l}
1 \\
1 \\
0 \\
0
\end{array}\right]^{\prime}\left[\begin{array}{l}
x_{1 t} \\
x_{2 t} \\
x_{3 t} \\
x_{4 t}
\end{array}\right], \\
{\left[\begin{array}{c}
\theta_{1 t} \\
\theta_{2 t} \\
\theta_{3 t} \\
\theta_{4 t}
\end{array}\right]=\left[\begin{array}{c}
\theta_{1}^{0} \\
\theta_{2}^{0} \\
0 \\
0
\end{array}\right]+\left[\begin{array}{cccc}
0 & 0 & \theta_{13}^{1} & \theta_{14}^{1} \\
0 & 0 & \theta_{23}^{1} & 0 \\
0 & 0 & 0 & 0 \\
0 & 0 & 0 & 0
\end{array}\right]\left[\begin{array}{c}
x_{1 t} \\
x_{2 t} \\
x_{3 t} \\
x_{4 t}
\end{array}\right] .}
\end{gathered}
$$

The first two factors $\left(x_{1 t}\right.$ and $\left.x_{2 t}\right)$ are considered to be latent - and are therefore backed out from the 3-month and 10-year yields (see below for details). The third and fourth factors $\left(x_{3 t}\right.$ and $\left.x_{4 t}\right)$ are observable factors representing bond market risk - calculated from interest rate options.

The blocks of zeros in (3) have two important implications. First, only the first two (latent) factors affect the short interest rate. For that reason the two last rows of $\theta^{0}$ and $\theta^{1}$ must be zeros - as we cannot identify "prices of risk" of factors that have no direct loadings on the short rate. In contrast, the assumption of $a_{1}=0$ and the unit loadings in $b_{1}$ are just normalisations. Second, only the last two factors $\left(x_{3 t}\right.$ and $\left.x_{4 t}\right)$ affect the market price of risk. To sharpen the identification, it is assumed the price of risk of the first factor $\left(\theta_{1 t}\right)$ is affected by both the third and fourth factors, while the price of risk of the second factor $\left(\theta_{2 t}\right)$ is affected only by the third factor.

Together, this means that an $n$-period yield has two main components: first, the "expectations hypothesis" part, that is, the average expected future short rate (driven by $x_{1 t}$ and $x_{2 t}$ ); second, the term premium part (driven by $x_{3 t}$ and $x_{4 t}$ ). The time-variation of the term premia depends on the parameters in $\theta^{1}$ and negative values will make the term premia increase when the risk factors do. The parameters in $\theta^{0}$ determine the average (over time) term premia. 


\section{Estimation Method}

This section describes how the option data is used to create proxies of bond market risk and how the yield curve model is estimated.

\subsection{Estimation of Bond Market "Risk"}

Option data captures market beliefs about future volatility - and is therefore a forward looking alternative to traditional measures of volatility such as predictions from GARCH models and realised volatility. This makes interest rate caps interesting proxies of bond market risk.

If the Black-Scholes model was correct, then the implied volatility would be the same for all cap rates - and equal to the standard deviation of the underlying riskneutral distribution of future interest rates. However, the implied volatilities in Figure 2 differ markedly across the cap rates, so another approach is warranted. I therefore use the data on the caps to estimate the shape of the distribution assuming that it can be approximated by a mixture of two lognormal distributions (Ritchey, 1990), and then construct a robust measure of volatility.

This approach gives a flexible distribution with few parameters (five: two means, two variances and the relative weight on the two mixture components). This riskneutral distribution can be motivated by assuming that the log pricing kernel and the log underlying asset price (here: the future interest rate) have a joint mixture-normal distribution, but with the restriction that the marginal distribution of the log pricing kernel is normal. The implication is that the cap price is

$$
C=\alpha G\left(\mu_{1}, \sigma_{1}^{2}\right)+(1-\alpha) G\left(\mu_{2}, \sigma_{2}^{2}\right)
$$

where $C$ is the price of the cap (obtained by inverting the formula used to calculate the implied volatilities), $\alpha$ is the weight on the first mixture component and $G()$ is a function that depends on the mean $\left(\mu_{i}\right)$ and the variance $\left(\sigma_{i}^{2}\right)$ of mixture component $i$. In case $\alpha=1$, then the result coincides with the BlackScholes formula. (See Söderlind and Svensson, 1997, and Söderlind, 2000, for details.)

In practice, this means that for a given cap maturity (1 year, say), all contracts with different cap rates (typically 9-11 different cap rates ranging from $0.5 \%$ to $5.5 \%$ ) on a trading day are used to estimate the five parameters in (4). This is done by minimizing the sum of squared pricing errors (non-linear least squares). The estimation is repeated for every trading day and every maturity of interest (the focus here is on the 1-year and the 5-year maturities). 
From these distributions, robust measures of volatility are constructed as the widths of $80 \%$ confidence bands (90th percentile minus the 10th percentile). The reason for this approach is that the data is able to pin-point the 10th and 90th percentiles with reasonable accuracy, but it gets progressively worse as we move further out in the tails as there are few/no cap rates out there.

The yield curve model estimation below uses the width of the $80 \%$ confidence band for the 1-year horizon (henceforth called "1-year bond market risk") and the difference between the $80 \%$ confidence band widths for the 5-year and 1-year horizons (henceforth called "term spread of bond market risk"). Both these factors are standardised to have zero means and approximately the same volatility as the yields. Since these risk measures are calculated from the riskneutral distributions of future yields, they incorporate market beliefs about future volatility and possibly also risk aversion.

\subsection{Estimation of the Yield Curve Model}

The yield curve model is estimated by maximum likelihood (MLE), assuming normally distributed errors. The two latent factors $\left(x_{1 t}, x_{2 t}\right)$ are backed out from (2) by treating the 3-month and 10-year yields, as well as the third and fourth factors $\left(x_{3 t}, x_{4 t}\right)$ as observable (see the appendix for details). The third factor $\left(x_{3 t}\right)$ is 1-year bond market risk and the fourth factor $\left(x_{4 t}\right)$ is the term spread of bond market risk (see Section 4.1).

The time series part of the likelihood function is defined in terms of the innovations of the four factors. All other (than the 3-month and 10-year) yields are treated as if they have "observation errors", so the cross-sectional part of the likelihood function is defined in terms their yield errors - where the fitted yields depend on the factors according to (2). (Details are in the appendix.)

It is well known that there are numerical issues with estimating yield curve models (see, for instance, Duffee, 2002). To overcome this, I apply a "small-tolarge" approach - and use the estimation results from the previous step as starting values in the estimation algorithm. In practice, I first estimated a one-factor model, then a two-factor model, later a 3-factor model and finally the 4-factor model - and the market prices of risk were also allowed to become more and more flexible. Initial estimates indicate that the first factor is a random walk, so this is imposed in the estimations reported below. This makes all the yields cointegrated, so MLE can be applied. Finally, a crude grid search is used to gauge indications of a local maximum.

The estimated parameters turn out to be strongly significant (reported in the appendix), but this finding should be taken with a grain of salt: the likelihood 
function is highly non-linear in the parameters and the estimation results indicate that the factors are very persistent. Both features make the properties of MLE (and the standard errors, in particular) unclear.

\section{Empirical Results}

This section presents the empirical results and performs the event study of how yields and term premia move on days with monetary policy decisions.

\subsection{Empirical Results: Implied Distributions}

Figure 3 illustrates estimation results from the 1- and 5-year interest rate caps. The upper panel shows the bond market risks calculated from the estimated distributions (90th minus 10th percentile). Overall, these measures of risk are higher in the middle of the sample than at either end of the sample. The results for the two horizons often show similar movements, but there are also important deviations - most easily seen in the lower panel which shows the term spread of bond market risk (the difference between the 5-and 1-year risks). For instance, the 5-year risk shoots up significantly on two occasions in 2003 while the 1-year risk does not. Conversely, the 1-year risk moved much more than the 5-year risk during the autumn of 2008.

By comparing the yields in Figure 1 with these results on bond market risk, it seems as if the yields for shorter (longer) maturities are positively correlated with 1 -year (5-year) risk. For instance, the 10-year yield seems to move in tandem with the 5-year risk for much of the period 2002-2006. This impression is verified by Table 2 which shows the correlations for 5 -day changes. It is also interesting to notice that the term spread (10-year yield minus 3-month yield) is strongly correlated with the 5 -year risk as well as with the term spread of the risks, but not much with the 1-year risk. 
Figure 3: Bond Market Risk Estimated from 1- and 5-Year Interest Rate Caps

The upper panel shows the bond market risk calculated from the estimated riskneutral distributions (90th minus 10th percentile). The lower panel shows the term spread of the bond market risk (5-year risk minus 1-year risk).
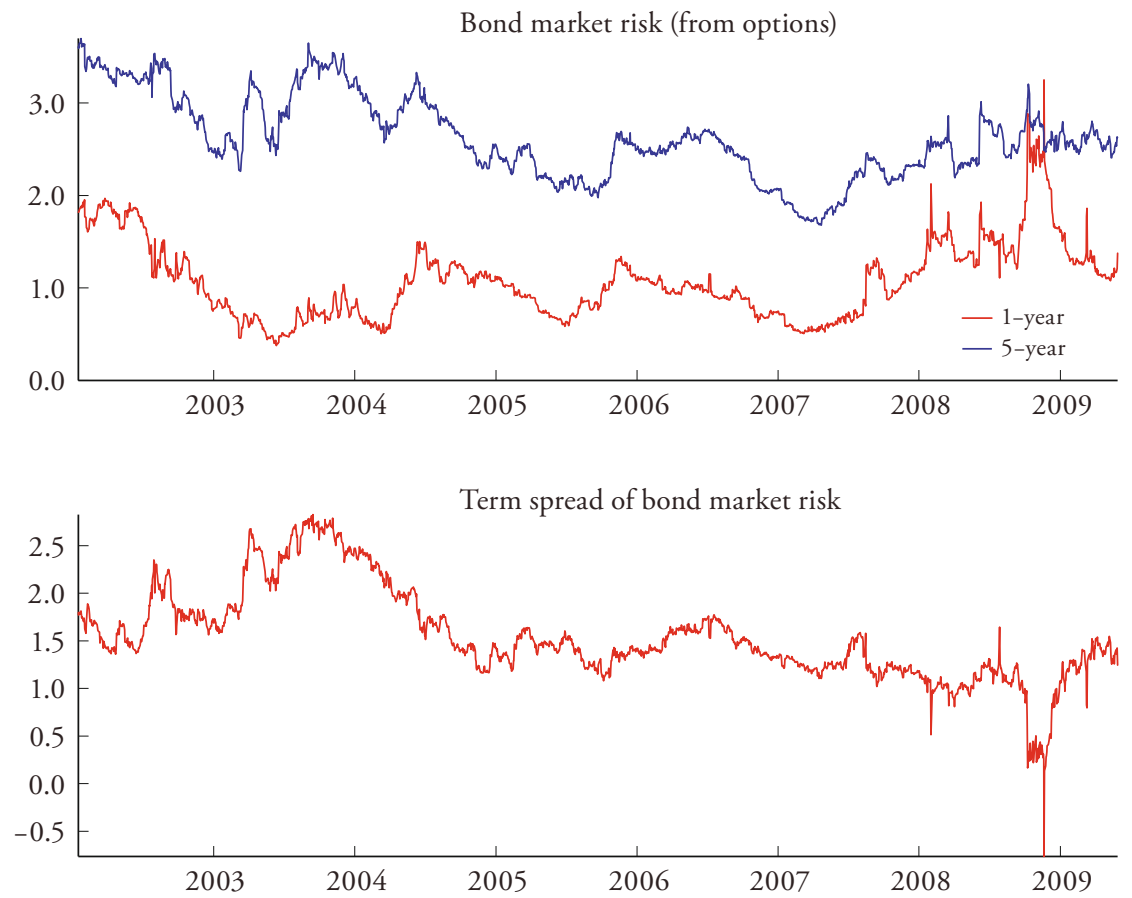

Table 2: Correlation between the 5-Day Change of Bond Market Risk and other Variables

This table shows the correlations of the 5-day change of the 1-year and 5-year bond market risks, with the 5-day change of other variables. The term spread is the 10-year minus 3-month yield.

1-year bond market risk 5-year bond market risk Term spread of bond market risk

\begin{tabular}{lccc}
\hline 3-month yield & 0.33 & 0.16 & -0.20 \\
10-year yield & 0.15 & 0.53 & 0.30 \\
Term spread & -0.08 & 0.40 & 0.42 \\
\hline
\end{tabular}




\subsection{Empirical Results: Yield Curve Model}

\section{Figure 4: Properties of the Estimated Yield Curve Model}

The upper left panel shows the time series of the fitted errors for two maturities ( 1 and 7 years).

The upper right panel shows the average yield curve in data and fitted values. The lower left panel shows the factor loadings for different maturities. The lower right panel shows the instantaneous forward term premia for different values of the risk factors: at the average values and at the average values plus 2 standard deviations of either the third ("high $x_{3}$ ") or fourth factor (“high $x_{4}$ ”).

Fitted yield errors

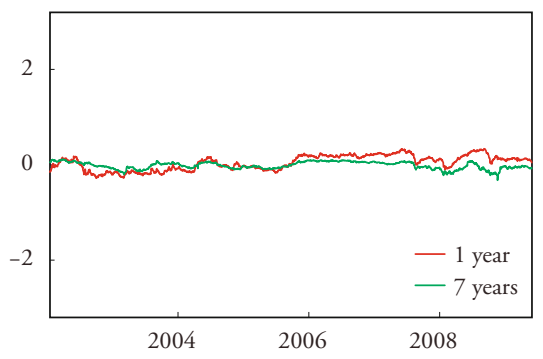

Factor loadings

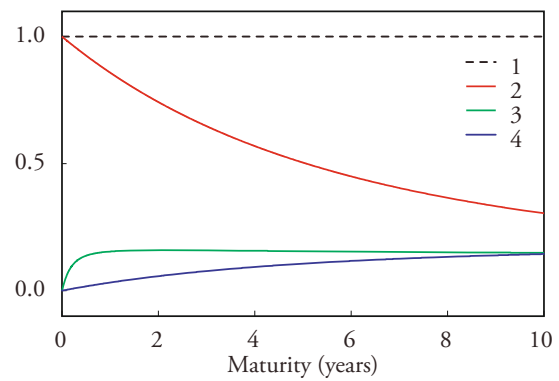

Average yield curve

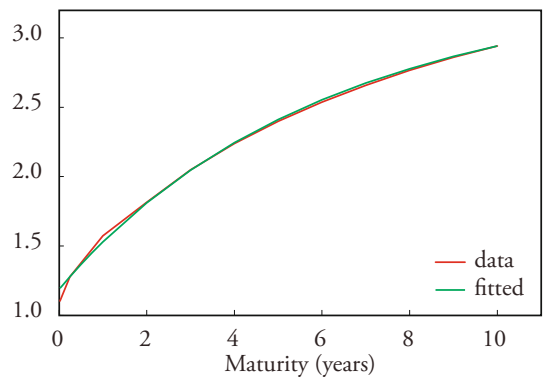

Term premia

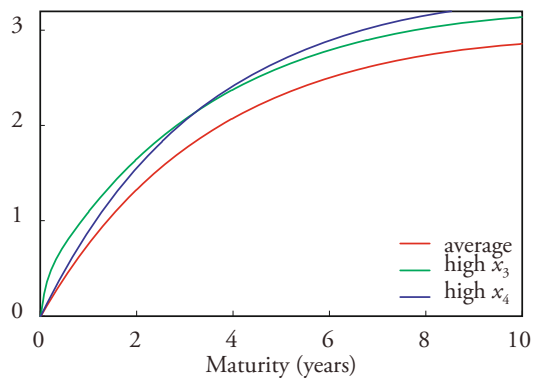

Figure 4 illustrates the estimated yield curve model. The upper left panel suggests that the pricing errors (only the 1- and 7-year maturities are shown) are typically small, while the upper right panel shows that the average yield curve implied by the model is very close to the data.

It is straightforward to show that the affine representation in (2) can be written.

$$
y_{n t}=a_{n}+b_{n 1} x_{1 t}+b_{n 2} x_{2 t}+b_{n 3} x_{3 t}+b_{n 4} x_{4 t},
$$


where

$$
b_{n 1}=1 \text { and } b_{n 2}=\frac{1-\rho_{2}^{n}}{n\left(1-\rho_{2}\right)} .
$$

The expressions for $b_{1 n}$ and $b_{2 n}$ incorporate the facts that the first factor is a random walk and that the second factor is an $\operatorname{AR}(1)$ with autocorrelation $\rho_{2}$. It can also be shown that (i) the $b_{n 1} x_{1 t}+b_{n 2} x_{2 t}$ part equals the average expected future short rate $\left(\sum_{s=0}^{n-1} \mathrm{E}_{t} y_{1, t+s} / n\right)$; (ii) $a_{n}$ equals the average term premium; and (iii) the $b_{n 3} x_{3 t}+b_{n 4} x_{4 t}$ part represents the time-variation of the term premium.

The lower left panel of Figure 4 shows these factor loadings. It is clear that the first factor (latent) generates the overall level of the entire yield curve (it is random walk, so $b_{1 n}=1$ for all maturities), while the second factor also latent) affects short maturities more than long maturities $\left(0<\rho_{2}<1\right)$ - and is therefore the main driver of the slope of the yield curve. Together, they represent the expectations part of the yield, that is, that part of the $n$-period yield that corresponds to the average expected future short rates. The third factor (1-year bond market risk) generates similar term premia for all yields except for the very shortest maturities ( $b_{n 3}$ is positive and similar for all maturities longer than 3 months). In contrast, the fourth factor - the term spread of bond market risk - has an impact $\left(b_{n 4}\right)$ that increases almost linearly with maturity. ${ }^{2}$

The lower right panel of Figure 4 shows what these factor loadings imply for the forward term premia. The average term premia increase with maturity - to fit the average slope of the yield curve. When the third factor is high (here 2 standard deviations above the mean) then the term premia increase for all maturities: the curve is almost a parallel upward shift of the curve for the average term premia. In contrast, when the fourth factor is high, then it is mostly the term premia for longer maturities that increase. It is thus the fourth factor that is the main driver behind the "term spread" of term premia (which is consistent with the pattern previously discussed in conjunction with Table 2).

Table 3 illustrates the relative importance of the different factors, by showing how much of the 1-day and 3-month forecast error variances that is due the four different factors. At the 3-month forecasting horizon, the first two (latent)

2 The estimated factors are very similar to the data discussed above. The first factor is very similar to the 10-year yield, while the second factor is almost the same as the negative of the terms spread (see Figure 1). The third factor is a standardised version of the 1-year bond market risk, and the fourth factor is a standardised version of the term spread of the bond market risk (see Figure 3). 


\section{Figure 5: Comparing the Model Output to Other Data}

The upper left panel plots the fitted innovations in the 3-month yield against the monetary policy surprises calculated from a 20-minute data window in RANALDO and Rossi (2010).

The upper right panel shows a (monthly) survey based forward term premium (3-month rate 3 months ahead in time) and the same term premium as implied by the estimated model. The survey based term premium is computed as the forward rate minus the 3-month forecast of the 3 -month Libor according to the panel of experts in the Consensus Forecast survey. The lower left panel shows the same thing, but for a 10 -year rate 1 year ahead in time.
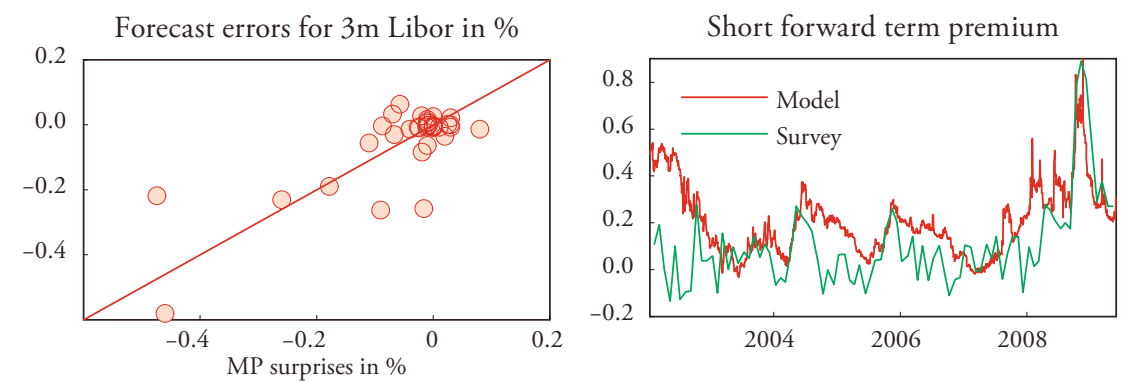

Long forward term premium

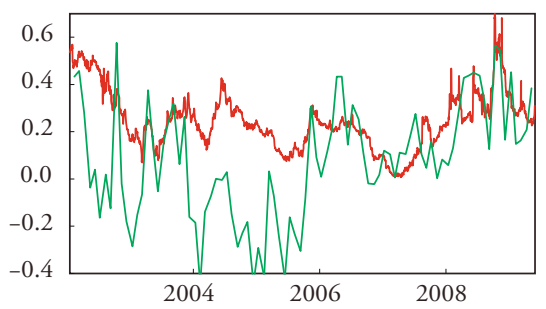

Table 3: Decomposition of Forecast Error Variances in \%

This table shows the decomposition of the forecast error variance for the 1-day and 3-month forecast horizons, for three different interest rates: $3 \mathrm{~m}$, 1y and $7 \mathrm{y}$ yields. The decomposition sums to $100 \%$, except for rounding.

\begin{tabular}{l|rrc|rrc|}
\hline & \multicolumn{3}{|c|}{ 1-day horizon } & \multicolumn{3}{c|}{ 3-month horizon } \\
& $3 \mathrm{~m}$ & $1 \mathrm{y}$ & $7 \mathrm{y}$ & $3 \mathrm{~m}$ & $1 \mathrm{y}$ & $7 \mathrm{y}$ \\
\hline Factor 1 & 41.2 & 43.5 & 61.0 & 44.7 & 49.3 & 70.5 \\
Factor 2 & 53.8 & 45.3 & 14.1 & 54.1 & 47.5 & 15.1 \\
Factor 3 & 5.0 & 10.8 & 14.9 & 1.2 & 2.7 & 3.8 \\
Factor 4 & 0.0 & 0.5 & 10.9 & 0.0 & 0.5 & 10.6 \\
\hline
\end{tabular}


factors each account for around half of the forecast errors for $3 \mathrm{~m}$ and $1 \mathrm{y}$ yields, while the third and fourth factors (bond market risk) are unimportant. In contrast, longer maturities like the $7 y$ yield is more tied to the first factor $(70.5 \%)$ and also influenced by the fourth factor (10.6\%). The results for the 1-day forecasting horizon are similar, except that they give a larger role for the third factor. Together with the previous results on the factor loadings, we can conclude that the expectations hypothesis accounts for most of the movements, but that the third factor induces some high-frequency changes in term premia for most yields (except the very short maturities) and the fourth considerable low-frequency term premia for long yields.

To further assess the fit of the model, Figure 5 compares the model output with data on monetary policy surprises and survey based term premia. The upper left panel suggests that the model's fitted one-day innovations of the 3-month yield are indeed similar to the monetary policy surprises (from RANALDO and Rossi, 2010) calculated from a 20-minute window around the announcement (the correlation is 0.77$){ }^{3}$ The upper right panel shows that the fitted term premia for the 3-month yield (for a forecasting horizon of 3 months) mostly moves in tandem with the risk premium implied by monthly survey data from Consensus Economics (on the days with survey data the correlation is 0.57 ). The lower left panel - for the 10-year yield, with a forecasting horizon of 1 year - shows somewhat larger discrepancies. Overall, this still lends some support to the validity of the model.

\subsection{Empirical Results: Event Study}

The estimated model has implications for many aspects of the yield curve (including predictability and pricing of derivatives), but the focus here is on the yield curve slope and the term premia. I use the model to simulate the typical behaviour of the yield curve in response to a change of the 3 -month yield. This is captured by a generalized impulse response function, which shows the reaction to a $1 \%$ increase in the 3-month yield - incorporating how all factors typically move in response to such an increase. (Technical details are in the appendix.)

On average days (based on the evidence from the full sample), the correlations of the first two factors and last two factors are virtually zero $(-0.09$ to 0.06). (This is indeed consistent with the model assumption that the factors are

3 The results are based on all dates with monetary policy decisions, except the annual General Meetings. Including also the days with the General Meetings gives very similar results. 
uncorrelated: $S$ in (1) is assumed to be a diagonal matrix.) Therefore, the typical response of the risk premium to changes in the 3 -month rate is zero.

However, on days of monetary policy decisions another pattern emerges as previously indicated in Table 1. I therefore perform a kind of event study by first estimating the covariances of the factor innovations on days with monetary policy decisions - and then use those to generate a typical scenario for monetary policy days. ${ }^{4}$ The basic assumption of this approach is that the interest rate decision is key mover on the monetary policy dates, so that the covariance patterns can be interpreted as the results of monetary policy surprises. This is plausible in most cases, but a few caveats are warranted. First, some of the monetary policy dates might be "contaminated" by important news from elsewhere. For instance, the interest rate decision on 8 October 2008 (coordinated across several central banks) could be such a case. Second, the effective sample for monetary policy dates is small: there are relatively few monetary policy dates in the sample (35) and the covariance estimates from those days are dominated by a number of sharp cuts in the policy rate. This suggests that the estimated effects reported below should only be considered as indicative.

The results are shown in Figure 6: the short rates increase as much as the policy rate, but the long rates actually decrease somewhat, so the yield curve is tilted downwards. The main reason is that the increase in the policy rate is expected to be long-lived, but not permanent: the expected future short rates are lower than the current rate. This affects the long yields via the expectations mechanism. However, the term premia also react to the policy shift. There is a small increase of the term premia (around $0.05 \%-0.08 \%$ ) for maturities up to a year, a zero effect at the two year maturity and around a sizeable decrease $(-0.25 \%)$ for the tenyear maturity. The reason is as follows. When the 3-month rate increases, then (on days with monetary policy decisions) there is typically a small increase in the third factor (1-year bond market risk) - which leads to a small increase of term premia for all maturities (compare with the lower panel of Figure 5). At the same time, there is typically also a marked decrease in the fourth factor ("term spread" of bond market risk) which decreases the term premia for the longer maturities. (This is clearly consistent with the evidence previously presented in Table 1.)

A key finding is thus that the estimated yield curve model shows that term premia for longer maturities tend to decrease in response to interest rate hikes. One possible interpretation is that higher policy rates reconfirm the credibility of the price stability target.

4 LENGWILER and LeNZ (2008) discuss how monetary policy is likely to affect several factors in a yield curve model. 
Figure 6: Reaction of Yields and Term Premia to a Monetary Policy Surprise

This figure shows the generalised impulse responses of yields, expected average future short yields and the yield term premium (yield minus the expected average 3-month yield until maturity), based on the covariance matrix of the factor innovations on days with monetary policy decisions.

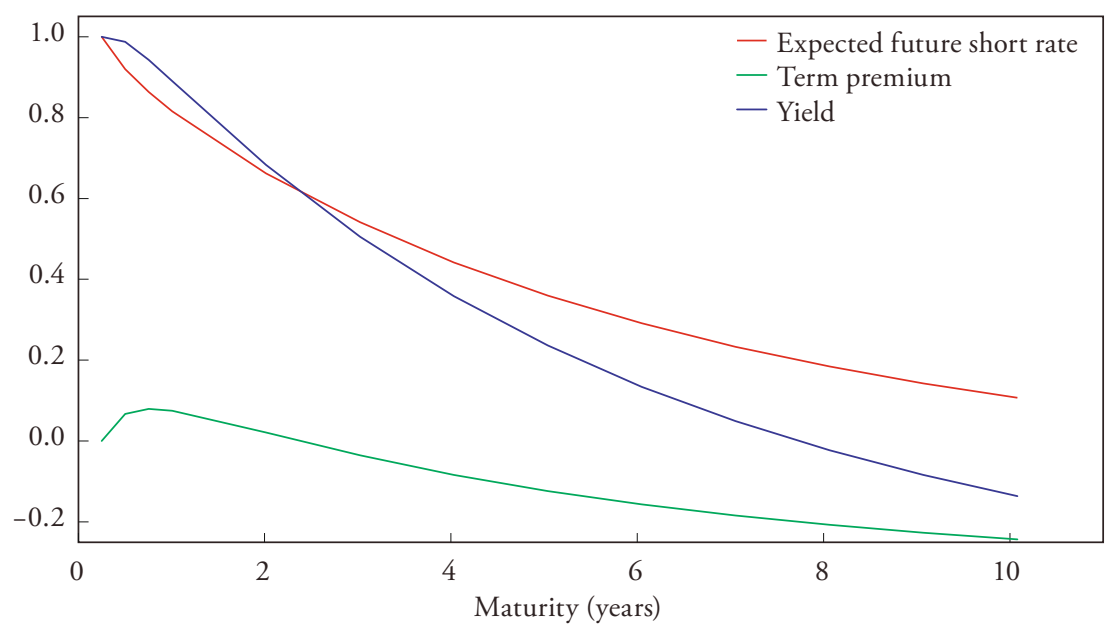

\section{Concluding Remarks}

How term premia react to monetary policy moves is an important question for both investors and analysts of the real effects of policy. This paper gives a partial answer by estimating a yield curve model on daily Swiss data for the period from January 2002 to May 2009 - and then calculating the impulse responses to an increase in the 3-month rate.

The model is an affine 4-factor model, where the first two factors are latent. The last two factors are based on data on interest rate options - and they are the drivers of the time variation of term premia. The estimated model generates innovations in the 3-month rate that are similar to external evidence of monetary policy surprises, as well as term premia that are consistent with survey data.

The results show that, on days with monetary policy surprises, there is a marked negative covariance between the policy move and the key option-based risk factor. Simulating such a scenario in the yield curve model gives term premia for long maturities that decrease in response to an interest rate hike.

Several things could be improved in this paper. First, the estimation results indicate close to non-stationarity for some of the (supposedly stationary) factors, 
which makes the inference shaky. A Monte-Carlo or Boot strap simulation could perhaps be useful. Another promising approach is to apply a Bayesian estimation method. Second, the external evidence on monetary policy surprises and expected future yields could possibly be used in the estimation (Kim and Orphanides, 2005; FISCHER, 2009). Third, the pricing implications for the interest rate caps could be explored and integrated into the estimation.

\section{A. Appendix}

\section{A.1 The Yield Curve Model}

The $A_{n}$ and $B_{n}$ values can be calculated as

$$
\begin{aligned}
& B_{n}^{\prime}=B_{n-1}^{\prime}\left(\Psi-S \theta^{1}\right)+b_{1}^{\prime} \\
& A_{n}=A_{n-1}+B_{n-1}^{\prime}\left[(I-\Psi) \mu-S \theta^{0}\right]-\frac{B_{n-1}^{\prime} S S^{\prime} B_{n-1}}{2}+a_{1},
\end{aligned}
$$

where the recursion starts at $B_{0}=0$ and $A_{0}=0$ (or $B_{1}=b_{1}$ and $\left.A_{1}=a_{1}\right)$. Then, define $a_{n}=A_{n} / n$ and $b_{n}=B_{n} / n$.

\section{A.2 Yield Curve Estimation}

Let $a_{n}=A_{n} / n$ and $b_{n}=B_{n} / n$. Collect the $K_{y}$ perfectly observable yields in the vector $y_{o t}$ and the $J$ yields with observation errors in $y_{u t}$. (2) can then be written

$$
\begin{aligned}
& y_{o t}=a_{o}+b_{o}^{\prime} x_{t} \\
& y_{u t}=a_{u}+b_{u}^{\prime} x_{t}+\varepsilon_{t},
\end{aligned}
$$

where $K$ factors are in the vector $x_{t}$ and $\varepsilon_{\mathrm{t}}$ are the observation errors.

The $K_{F}$ explicit factors $F_{t}$ and $y_{o t}$ can be used to back out the be $x_{t}$ vector as

$$
\begin{aligned}
& \underbrace{\left[\begin{array}{c}
y_{o t} \\
F_{t}
\end{array}\right]}_{\tilde{y}_{o t}}=\underbrace{\left[\begin{array}{c}
a_{o} \\
\mathbf{0}_{K_{F} \times 1}
\end{array}\right]}_{\tilde{a}_{o}}+\underbrace{\left[\begin{array}{ccc} 
& b_{o}^{\prime} \\
\mathbf{0}_{K_{F} \times K_{y}} & I_{K_{F}}
\end{array}\right]}_{\tilde{b}_{o}} x_{t}, \\
& \text { so } x_{t}=\tilde{b}_{o}^{-1}\left(\tilde{y}_{o t}-\tilde{a}_{o}\right) .
\end{aligned}
$$

(Clearly, the last $K_{F}$ elements of $x_{t}$ are identical to $F_{t}$.) 
The log likelihood function is

$$
\ln \mathcal{L}=\sum_{t=1}^{T} \ln p d f\left(y_{o t}, F_{t} \mid y_{o, t-1}, F_{t-1}\right)+\ln p d f\left(y_{u t} \mid y_{o t}, F_{t}\right),
$$

where the first part captures the one-period innovations in $y_{o t}$ and $F_{t}$ and the second part the cross-sectional errors in $y_{u t}\left(y_{u t}-a_{u}-b_{u}^{\prime} x_{t}\right)$. Both probability density functions $(p d f)$ are assumed to be Gaussian with zero means. For the one-period innovations, the covariance matrix is driven by $S$ in (1) and also the mapping from $x_{t}$ to $\left(y_{o t}, F_{t}\right)$ - see above. For the cross-sectional pricing errors, it is assumed that the covariance matrix is $\omega^{2} I_{J}$, where $\omega$ is a scalar. That is, the observation errors are assumed to be uncorrelated and have the same variances.

The first factor is assumed to be a random walk, so $\rho_{1}$ is set to unity. This means that the yields are cointegrated. To restrict factors $2-4$ to be stationary, the autoregressive parameters $\left(\rho_{i}\right.$, the diagonal elements of $\Psi$ ) are transformed by a logistic function. This means that the optimization algorithm searches for the optimal $r_{i}$ and the autoregressive parameter is defined as $\rho_{i}=1-2 /\left[1+\exp \left(r_{i}\right)\right]$, which restricts $\rho_{i}$ to be between -1 and 1 .

The parameter estimates are given in Table 4 . Notice that the somewhat unusual scale of the price of risk parameters is due to use of daily data. Similarly, the autocorrelation parameters are very high due to daily data, but the implication for long maturities is different. For instance, for $\rho_{2}$ notice that $0.9987^{2500}=0.0387$ so the effect on the 10-year yield of the second factor is almost zero.

\section{Table 4: Parameter Estimates}

This table shows the estimated parameters and t-stats. $\rho_{i}$ is the $i$-th diagonal element in the $\boldsymbol{\Psi}$ matrix and $\sigma_{i}$ in the $S$ matrix. All $\sigma_{i}$ and also $\omega$ are annualised and expressed in percent by multiplying with $250 \times 100$.

\begin{tabular}{lcc}
\hline & coef & std \\
\hline$\theta_{1}{ }^{0}$ & -0.0074 & 0.0002 \\
$\theta_{2}{ }^{0}$ & -0.0579 & 0.0253 \\
$\rho_{1}$ & 1 & \\
$\rho_{2}$ & 0.9987 & 0.0000 \\
$\rho_{3}$ & 0.9637 & 0.0008 \\
$\rho_{4}$ & 0.9985 & 0.0001 \\
$\sigma_{1}$ & 0.0463 & 0.0007
\end{tabular}




\begin{tabular}{lrr}
\hline & \multicolumn{1}{c}{ coef } & \multicolumn{1}{c}{ std } \\
\hline$\sigma_{2}$ & 0.0551 & 0.0008 \\
$\sigma_{3}$ & 0.1503 & 0.0013 \\
$\sigma_{4}$ & 0.1497 & 0.0013 \\
$\omega$ & 0.1495 & 0.0004 \\
$\theta_{13}{ }^{1}$ & -2707.3848 & 105.3537 \\
$\theta_{14}{ }^{1}$ & -154.5826 & 5.6224 \\
$\theta_{23}{ }^{1}$ & -653.7320 & 64.5276 \\
\hline
\end{tabular}

\section{A.3 The Generalized Impulse Response Function}

Let $\varepsilon_{t}$ be the vector of shocks and use the following values as the impulse: $E\left(\varepsilon_{t} \mid \varepsilon_{i t}=1\right)=\Sigma_{i} / \sigma_{i i}$, where $\Sigma_{i}$ is column $i$ of the covariance matrix of $\varepsilon_{t}$ and $\sigma_{i i}$ is the variance of $\varepsilon_{i t}$. This means that the value of the entire vector $\varepsilon_{t}$ is predicted (assuming that $\varepsilon_{t}$ is normally distributed) using the information $\varepsilon_{i t}=1$ (see Pesaran and Shin, 1998, for details). Clearly, when the shocks are uncorrelated, then coincides with a traditional impulse response function (where the impulse is $\varepsilon_{i t}=1$ and $\varepsilon_{j t}=0$ for $j \neq i$ ).

\section{References}

Ang, A., and M. Piazzesi (2003), "A No-Arbitrage Vector Autoregression of Term Structure Dynamics with Macroeconomic and Latent Variables", Journal of Monetary Economics, 60, pp. 745-787.

Bolder, D. J., and S. Liu (2007), "Examiniming Simple Joint Macroeconomic and Termstructure Models: A Practitioner's Perspective”, Working Paper 200749, Bank of Canada.

Chun, A. L. (2005), "Expectations, Bond Yields and Monetary Policy", mimeo, Stanford University.

Diebold, F. X., and C. Li (2003), "Forecasting the Term Structure of Government Yields", mimeo, University of Pennsylvania.

Duffee, G. R. (2002), "Term Premia and Interest Rate Forecasts in Affine Models", Journal of Finance, 57, pp. 405-443.

FIscher, M. (2009), "The Relationship between German and US Risk Premia", mimeo, University of St. Gallen. 
Hördahl, P., O. Tristiani, and D. Vestin (2006), "A Joint Econometric Model of Macroeconomic and Term Structure Dynamics", Journal of Econometrics, 131, pp. 405-444.

Kim, D. H., and A. Orphanides (2005), "Term Structure Estimation with Survey Data on Interest Rate Forecasts", DP 5341, CEPR.

Lengwiler, Y., and C. Lenz (2010), "Intelligible Factors for the Yield Curve", Journal of Econometrics, forthcoming.

Lildholdt, P., N. Panigirtzoglou, and C. Peacock (2007), "An Affine Macro-Factor Model of the UK Yield Curve", Working Paper 322, Bank of England.

Pesaran, H. H., and Y. Shin (1998), "Generalized Impulse Response Analysis in Linear Multivariate Models", Economics Letters, 58, pp. 17-29.

Ranaldo, A., and E. Rossi (2010), "The Reaction of Financial Assets to Swiss National Bank Communication”, Journal of International Money and Finance, forthcoming.

Ritchey, R. J. (1990), "Call Option Valuation for Discrete Normal Mixtures", Journal of Financial Research, 13, pp. 285-296.

SöDerlind, P. (2000), "Market Expectations in the UK before and after the ERM Crisis", Economica, 67, pp. 1-18.

SöDerlind, P., and L. E. O. Svensson (1997), "New Techniques to Extract Market Expectations from Financial Instruments”, Journal of Monetary Economics, 40, pp. 383-429.

\section{SUMMARY}

An affine yield curve model is estimated on daily Swiss data 2002-2009. The market price of risk is modelled in terms of proxies for uncertainty, which are estimated from interest rate options. The estimated model generates innovations in the 3-month rate that are similar to external evidence of monetary policy surprises - as well as term premia that are consistent with survey data. The results indicate that a surprise increase in the policy rate gives a reasonably sized decrease $(-0.25 \%)$ in term premia for longer maturities. 